\title{
Vector Concentration used for Stenosis Assessment in the Carotid Artery before and after Carotid Stenting
}

Brandt, Andreas Hjelm; Nguyen, Tin-Quoc; Gutte, Henrik; Holtmannspötter, Markus; Moshavegh, Ramin; Jensen, Jørgen Arendt; Nielsen, Michael Bachmann; Lindskov Hansen, Kristoffer

\section{Published in:}

Proceedings of the 2019 IEEE International Ultrasonics Symposium

Link to article, DOI:

10.1109/ultsym.2019.8925731

Publication date:

2019

Document Version

Peer reviewed version

Link back to DTU Orbit

Citation (APA):

Brandt, A. H., Nguyen, T-Q., Gutte, H., Holtmannspötter, M., Moshavegh, R., Jensen, J. A., Nielsen, M. B., \& Lindskov Hansen, K. (2019). Vector Concentration used for Stenosis Assessment in the Carotid Artery before and after Carotid Stenting. In Proceedings of the 2019 IEEE International Ultrasonics Symposium (pp. 348-351). [MoPoS-03.4] IEEE. https://doi.org/10.1109/ultsym.2019.8925731

\section{General rights}

Copyright and moral rights for the publications made accessible in the public portal are retained by the authors and/or other copyright owners and it is a condition of accessing publications that users recognise and abide by the legal requirements associated with these rights.

- Users may download and print one copy of any publication from the public portal for the purpose of private study or research.

- You may not further distribute the material or use it for any profit-making activity or commercial gain

- You may freely distribute the URL identifying the publication in the public portal 


\section{Vector Concentration used for Stenosis Assessment in}

\section{the Carotid Artery before and after Carotid Stenting}

\author{
Andreas Hjelm Brandt \\ Dept. of Diagnostic Radiology \\ Rigshospitalet \\ Copenhagen, Denmark \\ andreaskr5@gmail.com
}

\author{
Tin-Quoc Nguyen \\ Dept. of Diagnostic Radiology \\ Rigshospitalet \\ Dept. of Clinical Medicine \\ University of Copenhagen \\ Copenhagen, Denmark \\ tin-quoc.nguyen.02@regionh.dk
}

\author{
Ramin Moshavegh \\ Bk Medical \\ Herlev, Denmark \\ RMosehavegh@bkmedical.com \\ Jørgen Arendt Jensen \\ Department of Health Technology \\ Technical University of Denmark \\ Lyngby, \\ jaj@elektro.dtu.dk
}

\author{
Henrik Gutte \\ Dept. of Diagnostic Radiology \\ Rigshospitalet \\ Copenhagen, Denmark \\ onh.dk \\ Michael Bachmann Nielsen \\ Dept. of Diagnostic Radiology \\ Rigshospitalet \\ Dept. of Clinical Medicine \\ University of Copenhagen \\ Copenhagen, Denmark \\ mbn@dadlnet.dk
}

henrik.gutte.borgwardt.04@regi markus.holtmannspoetter@regionh

\author{
Marcus Holtmannspötter \\ Dept. of Diagnostic Radiology \\ Rigshospitalet \\ Copenhagen, Denmark \\ .dk
}

Kristoffer Lindskov Hansen

Dept. of Diagnostic Radiology Rigshospitalet

Dept. of Clinical Medicine

University of Copenhagen

Copenhagen, Denmark

kristoffer.lindskov.hansen.01 @regionh.dk

\begin{abstract}
Angiography of carotid stenosis is the preferred method for stenosis assessment, but the method is invasive and ionizing. The ultrasound technique Vector Flow Imaging (VFI) is proposed as a noninvasive and nonionizing alternative for stenosis assessment. Vessel stenosis and flow complexity are associated, and VFI can measure flow complexity with Vector Concentration (VC). VC goes towards 1 for laminar flow and 0 for complex flow. In this preliminary study, 5 patients treated with carotid stent for carotid artery stenosis were examined with VFI to evaluate if VC estimations were comparable with the corresponding digital substraction angiography (DSA) calculated stenosis degree percentage. VFI was obtained with a bk5000 ultrasound scanner and an $8 \mathrm{~L} 2$ linear transducer with a frequency range from 2-8 MHz (BK Medical, Herlev, Denmark), while angiography data were obtained with Siemens Artis Q (Siemens, Erlangen, Germany). The flow in the stenosis was evaluated with $\mathrm{VC}$ as a mean over 100 frames with a frame rate of $30 \mathrm{~Hz}$. VC of the stenotic carotid artery was low for all patients before stenting with a mean of 0.59 (SD:0.07), while mean $\mathrm{VC}$ increased to 0.97 (SD:0.02) after stenting $(p=0.016)$. Mean DSA stenosis degree percentage was $82 \%$ (SD:9\%) before stenting and was reduced to $11 \%$ (SD:6\%) after stenting $(p=0.001)$. Correlation coefficient between $\mathrm{VC}$ and DSA stenosis degree was strong 0.97 . This is the first preliminary study that shows VFI can be used to evaluate stent treatment of carotid stenosis. The results indicate that $\mathrm{VC}$ is a useful parameter for flow complexity assessment, and that $\mathrm{VC}$ and stenosis degree are comparable for patients with carotid stenosis.
\end{abstract}

Keywords-Carotid Stenosis, Vector Flow Imaging, Vector Concentration, Digital Subtraction Angiography

\section{INTRODUCTION}

Ischaemic stroke is often caused by carotid artery stenosis and exact diagnosis can reduce the risk of stroke [1]. Digital subtraction angiography (DSA) is considered the preferred method for carotid stenosis assessment; however, the procedure is invasive and accompanied by a high ionizing radiation for the patient and medical staff $[2,3]$.

Doppler ultrasound is considered the initial choice for assessment of carotid artery stenosis. Degree of stenosis is determined by peak velocity and velocity ratio estimation with spectral Doppler, where the ratio is calculated based on the increase in peak systolic velocity between a stenosis and the adjacent normal lumen segment [4]. However, one major disadvantage of Doppler ultrasound is the angle dependency, as only the velocities along the axis of emitted beam are estimated. This means angle correction must be performed to obtain quantitative flow values. Angle correction can be incorrect, since complex flow may change the flow direction in a cardiac cycle [5]. Furthermore, Doppler ultrasound is highly operator dependent and has a low interobserver agreement $[4,6]$.

The ultrasound technique vector flow imaging (VFI) is an angle-independent ultrasound technique for velocity estimation [7], which has recently been proven to be less operator dependent and to have a superior intra- and interobserver agreement compared with conventional spectral Doppler ultrasound [8-10]. VFI estimates the axial and transverse velocity components of the blood flow from which a $2 \mathrm{D}$ vector velocity can be determined $[11,12]$. Besides velocity estimation, VFI can be applied for vector concentration (VC) estimation, a VFI derived parameter for flow complexity 
assessment [13]. Complex flow defined with vector flow has been connected with difference in the diameters of the carotid artery [14], and VC correlated strongly with DSA for stenosis degree assessment of the superficial femoral artery [15], and to peak velocities obtained with transesophageal echocardiography for evaluation of aortic valve stenosis [16].

In this preliminary study, patients with symptomatic significant carotid stenosis ( $>70 \%$ stenosis degree) were examined with VFI and DSA. The aim of the study was to compare VC obtained with VFI with the stenosis degree percentage obtained with DSA before and after stenting. The hypothesis was that $\mathrm{VC}$ is able to detect a significant carotid stenosis and assess the effect of stenting.

\section{MATERIALS AND MethodS}

\section{A. Study population}

Five patients ( 3 men, 2 women, mean age: 62.8 years, range: 47-81 years) with common carotid stenosis (CCA) or proximal internal carotid stenosis (ICA) were included. Stenosis degree was determined beforehand with computed tomography angiography (CTA) and inclusion criteria were stenosis degree $>70 \%$ of the vessel diameter. All patients presented with ipsilateral mild neurological symptoms and were treated with carotid artery stenting within a week after symptom debut. The local ethics committee waived approval, since ultrasound is considered a routine examination for these patients (no. H19009278).

\section{B. Scan Setup}

A commercial scanner (bk5000, BK Medical, Herlev, Denmark) equipped with a linear transducer with a frequency range of 2-8 $\mathrm{MHz}$ (8L2, BK Medical, Herlev, Denmark) was used for the ultrasound examinations. All patients were scanned in the angiography room just before and after DSA examination and stent treatment. The ultrasound scans included examination of the prestenotic and stenotic region. Complex flow was detected in the long-axis view with VFI, where vortices or sudden aliasing complex flow indicated a stenotic region. PRF was set to the lowest possible value with no aliasing on the scanner display, while optimal filling of the vessel was ensured at the same time. Video sequences were obtained with the vessel centered in the scan plane (Fig. 1). The flow in the stenosis was evaluated with VC as a mean over 100 frames with a frame rate of $30 \mathrm{~Hz}$. Blooming artefacts were avoided with adjusting wall filter and color gain. All other settings stayed in default mode. Insonation angle was 70-90 degrees in all cases. Maximum scan depth was approximately $3 \mathrm{~cm}$. The VFI video sequences were processed offline in MATLAB (MathWorks, Natick, MA, USA) with an in-house developed algorithm as previously described $[13,17]$.

\section{VFI and Vector concentration}

Both the axial and transverse velocity components are found with VFI. The axial direction is found as in conventional Doppler ultrasound, while motions in the transverse direction is found by using a changed apodization in receive beamforming [12]. Mean VC in the CCA or ICA was found across at least 5 consecutive systoles. Region of interest (ROI) used for VC estimation included the stenotic area with turbulent flow (Fig. 1). VC was calculated as the vector angle spread within the
ROI. VC goes towards 1 in laminar flow and towards 0 for complex flow. Previous papers provide detailed explanations of the VC calculation $[13,15,18]$.

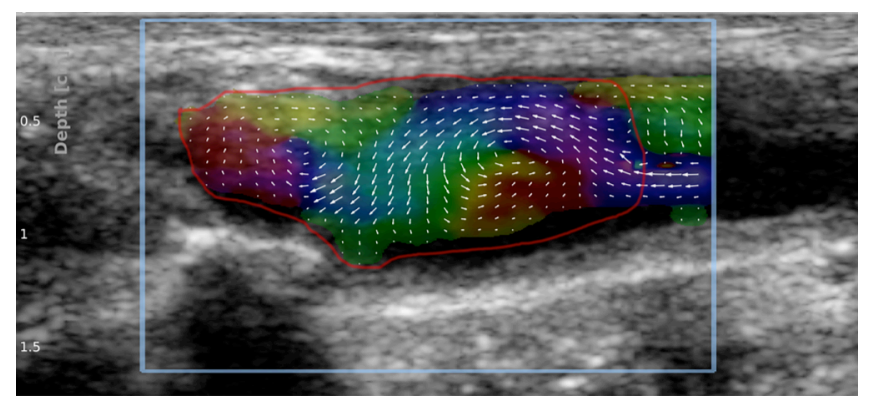

Fig. 1. Vector flow imaging of the carotid stenosis before stenting showing complex flow in the stenotic area for patient 1 . Vector concentration was calculated within a region of interest delinated by the red line.

\section{DSA and Stent treament}

A Siemens Artis Q biplane angiography system (Siemens, Siemens Healthcare GmbH, Erlangen, Germany) was used to perform the DSA examination and stent treatment. A biaxial system was used for the DSA examination. A 6- or 9-Fr sheath was placed in the femoral artery with a 4- or 5-Fr diagnostic catheter for contrast injections. Angiography in two planes of the carotid artery was performed at 2 frames/s and during intravenous iodine contrast injection (Visipaque $270 \mathrm{mgI} / \mathrm{ml}$, GE Healthcare). All patients were uneventful treated with a Casper carotid stent (Microvention inc., Aliso Viejo, Californien, USA) covering the stenotic area (Fig. 2). The DSA images that yielded the most severe diameter reduction were used for calculation of the stenosis degree percentage (Fig. 3). Stenosis degree percentage was calculated according to The European Carotid Surgery Trial (ECST) method [19].

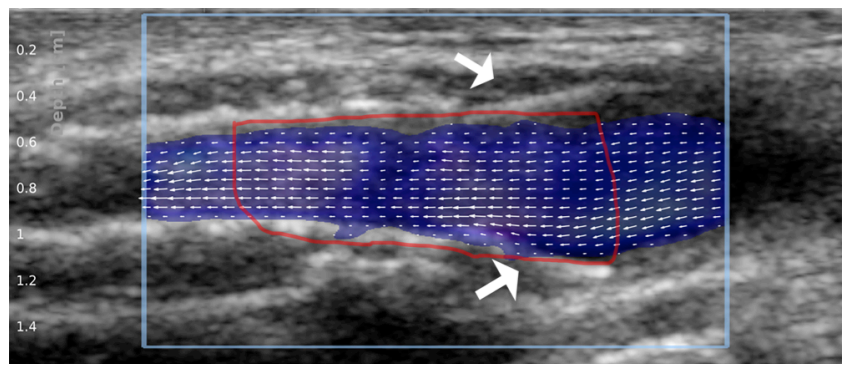

Fig. 2. Vector flow imaging of the carotid artery after stenting for patient 1. The stent is marked with white arrows. The flow complexity is noticeably reduced. Calculation of vector concentration revealed an almost perfect laminar flow.

\section{E. Statistical analysis}

Mean VC and standard deviation (SD) were calculated for all patients. VC and DSA stenosis degree before stent treatment were compared with VC and DSA stenosis degree after stent treatment using a paired 2-tailed t-test. A p $<0.05$ value was considered significant. Correlation coefficient was calculated between VC and DSA stenosis degree. Statistical analyses were performed with IBM SPSS Statistics (SPSS Inc., Chicago, IL, USA). 


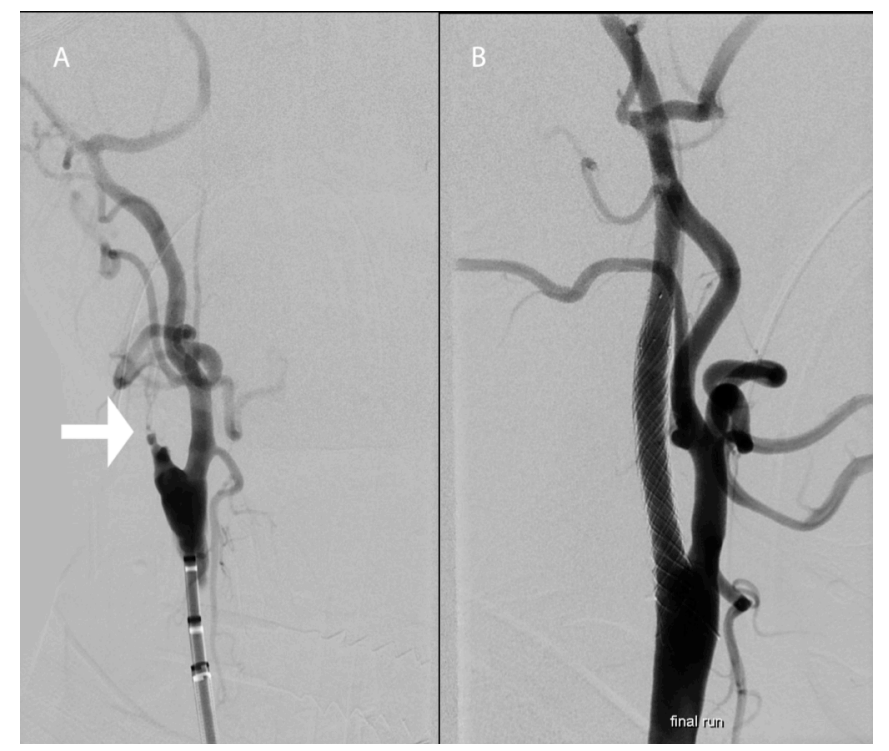

Fig. 3. The arrow in image A marks the stenotic part of the internal carotid artery, while image B shows the same segment after stent treament. (Patient 1).

\section{RESUlTS}

An overview of VC values and DSA stenosis degree percentage are given in table 1 . VC of the stenotic carotid artery was low for all patients before stenting with a mean of 0.59 (SD:0.07), while mean VC increased to 0.97 (SD:0.02) after stenting $(p=0.016)$. Mean DSA stenosis degree percentage was $82 \%$ (SD:9\%) before stenting and reduced to $11 \%$ (SD:6\%) after stenting $(p=0.001)$. Correlation coefficient between VC and DSA stenosis degree was strong 0.97.

TABLE I. VECTOR CONCENTRATION AND CORRESPONDING STENOSIS DEGREE

\begin{tabular}{|l|l|l|l|l|}
\hline Patient & $\begin{array}{l}\text { VC - } \\
\text { before } \\
\text { stenting }\end{array}$ & $\begin{array}{l}\text { VC - } \\
\text { after } \\
\text { stenting }\end{array}$ & $\begin{array}{l}\text { Stenosis } \\
\text { degree - } \\
\text { before } \\
\text { stenting }\end{array}$ & $\begin{array}{l}\text { Stenosis } \\
\text { degree - } \\
\text { after } \\
\text { stenting }\end{array}$ \\
\hline 1 (ICA) & 0.56 & 0.98 & $93 \%$ & $5 \%$ \\
\hline 2 (CCA) & $\mathbf{0 . 6 1}$ & 0.95 & $86 \%$ & $14 \%$ \\
\hline 3 (ICA) & $\mathbf{0 . 6 8}$ & 0.98 & $73 \%$ & $18 \%$ \\
\hline 4 (CCA) & 0.49 & 0.99 & $85 \%$ & $11 \%$ \\
\hline 5 (CCA) & 0.62 & 0.96 & $73 \%$ & $5 \%$ \\
\hline
\end{tabular}

\section{DISCUSSION}

$\mathrm{VC}$ is a new parameter for blood flow evaluation in carotid artery stenosis and stent monitoring. VC was able to identify significant stenosis in the carotid artery and stent flow, with DSA used as reference. The results in this study are in line with previous studies with VC for flow assessment $[15,16]$.

Complex flow can also be assessed with spectral broadening in spectral Doppler or by evaluating mosaic patterns in color Doppler mapping [20]. However, for both methods, the assessment is qualitatively opposed to $\mathrm{VC}$, where quantitative values are obtained about the flow. VFI provides more data for flow evaluation, than conventional Doppler, since every pixel within the ROI is used for flow assessment. Furthermore, quantitative flow evaluation by estimation of vector complexity using dual-angle plane wave by Saris et al. [21] has similar to studies with VC show promising results, indicating vector complexity assessment can be a valuable parameter for flow assessment in stenotic vessels.

VC has several advantages compared to peak velocity estimation with spectral Doppler. Calcified plaques in the vessel wall of the carotid artery may hinder the evaluation of blood flow with ultrasound, since the flow can be hidden by shadows impeding peak flow alignment for peak velocity estimation [15]. VC is not dependent on alignment, since flows from all directions in the ROI are used to quantify the flow. All flow components in the stenosis and adjacent to the stenotic area are used for VC calculation, meaning that VC also is less sensitive to shadowing from calcified plaques. Furthermore, peak velocity estimation is impaired by PRF sensitivity $[15,22]$. VC is less affected by PRF, as not only the peak flow is used for the estimation, but also the adjacent flow components not affected by aliasing. This has been shown by Hansen et al. [16] However, the most obvious advantage compared with spectral Doppler is the angle-independent flow estimation of VFI. Concerns about insonation angle and angle correction are unnecessary with VFI for carotid flow evaluation [9, 23].

There has been some discussion about spectral Doppler obtained velocities applied for non-stented carotid arteries may not apply for stented carotid arteries [24]. The flow in a stented artery change slightly, which may be caused by reduced compliance. The mechanisms of the flow alternations are not well understood [25]. Vector complexity assessment with VC could potentially elucidate this subject.

CTA and magnetic resonance imaging (MRI) are other noninvasive imaging modalities for carotid artery stenosis assessment $[26,27]$. Contrary to ultraosund CTA is immobile and accompanied with ionizing radiation, while MRI is time consuming, immobile, and the evaluation is not performed in real time. Ultrasound is widely available and often first-line imaging modality for evaluation of hemodaynamic status in the carotid artery and is used in the treatment decision [28]. Adding the ultrasound-derived VC parameter is therefore obvious for diagnosing carotid artery stenosis and monitoring stented carotid arteries.

Some limitations should be acknowledged in this preliminary study. The most obvious limitation is the small study population. Secondly, alignments with DSA recordings were not done exactly. Differences in the distance from the bifurcation can change the velocity and probably also the complexity of the flow [29]. Additionally, this study only considered patients with significant carotid stenosis $(>70 \%$ stenosis degree). A study concerning numerous stenosis degrees would enlighten VC correlation with carotid artery stenosis degree percentage. 


\section{CONCLUSION}

This is the first preliminary study indicating that VFI can be used to evaluate stent treatment of carotid stenosis. The results imply that VC could potentially be a nonionizing and noninvasive clinical tool for stenosis assessment in patients with vascular diseases such as carotid artery stenosis. Furthermore, $\mathrm{VC}$ could be crucial in the decision of stent treatment.

\section{ACKNOWLEDGMENT}

The authors wish to thank all participating patients. The study was supported by BK Medical.

\section{REFERENCES}

[1] J. F. Meschia, J. P. Klaas, R. D. Brown Jr., and TG Brott, "Evaluation and Management of Atherosclerotic Carotid Stenosis," Mayo Clinic Proceedings, vol. 92, no. 7, pp. 1144-1157, 2017.

[2] T. Adla and R. Adlova, Multimodality Imaging of Carotid Stenosis; "The International journal of angiology : official publication of the International College of Angiology," Inc. , vol. 24, no. 3, pp. 179-184, 2015.

[3] W. A. Chilcote, M. T. Modic, W. A. Pavlicek, J. R. Little, A. J. Furlan, P M. Duchesneau, et al., "Digital subtraction angiography of the carotid arteries: a comparative study in 100 patients," Radiology, vol. 139, no. 2, pp. $287-295,1981$.

[4] E. G. Grant, C. B. Benson, G. L. Moneta, A. V. Alexandrov, J. D. Baker, E. I. Bluth, et al., "Carotid artery stenosis: gray-scale and Doppler US diagnosis--Society of Radiologists in Ultrasound Consensus Conference," Radiology, vol. 229, no. 3, pp. 340-346.

[5] P. R. Hoskins, "A comparison of single- and dual-beam methods for maximum velocity estimation," Ultrasound in Medicine \& Biology, vol. 24, no. 4, pp. 583-592, 1999.

[6] M. M. Corriveau and K. W. Johnston, "Interobserver variability of carotid Doppler peak velocity measurements among technologists in an ICAVL-accredited vascular laboratory," Journal of Vascular Surgery, vol. 39, no. 4, pp. 735-741, 2004

[7] J. A. Jensen and P. Munk, "A new method for estimation of velocity vectors," IEEE transactions on Ultrasonics, Ferroelectrics, and Frequency Control, vol. 45, no. 3, pp. 837-851, 1998.

[8] M. M. Pedersen, M. J. Pihl, P. Haugaard, J. M. Hansen, K. L. Hansen, M. B. Nielsen, et al., "Comparison of real-time in vivo spectral and vector velocity estimation," Ultrasound in Medicine \& Biology, vol. 39, no. 1, pp. 145-151.

[9] A. H. Brandt, K. L. Hansen, C. Ewertsen, S. Holbek, J. B. Olesen, R. Moshavegh, et al, "A Comparison Study of Vector Velocity, Spectral Doppler and Magnetic Resonance of Blood Flow in the Common Carotic Artery," Ultrasound in Medicine \& Biology, vol. 44, no. 8, pp. 1751$1761,2018$.

[10] A. H. Brandt, R. Moshavegh, K. L. Hansen, T. Bechsgaard, L. Lonn, J. A. Jensen, et al., "Vector Flow Imaging Compared with Pulse Wave Doppler for Estimation of Peak Velocity in the Portal Vein," Ultrasound in Medicine \& Biology, vol. 44, no. 3, pp. 593-601, 2018.

[11] J. Udesen J and J. A. Jensen, "Investigation of transverse oscillation method," IEEE transactions on Ultrasonics, Ferroelectrics, and Frequency Control, vol. 53, no. 5, pp. 959-971, 2006.

[12] J.A. Jensen, "A new estimator for vector velocity estimation [medical ultrasonics], " Ultrasonics, Ferroelectrics and Frequency Control, IEEE Transactions on, vol. 48, no. 4, pp. 886-894, 2001.

[13] M. M. Pedersen, M. J. Pihl, P. Haugaard, K. L. Hansen, T. Lange, L. Lonn, et al., "Novel flow quantification of the carotid bulb and the common carotid artery with vector flow ultrasound," Ultrasound in Medicine \& Biology, vol. 40, no. 11, pp. 2700-2706, 2014.
[14] A. Goddi, C. Bortolotto, M. V. Raciti, I. Fiorina, L. Aiani, G. Magistretti, et al., "High-Frame Rate Vector Flow Imaging of the Carotid Bifurcation in Healthy Adults: Comparison With Color Doppler Imaging," Journal of ultrasound in medicine : official journal of the American Institute of Ultrasound in Medicine, vol. 37, no. 9, pp. 2263-2275, 2018.

[15] K. L. Hansen, P. M. Hansen, C. Ewertsen, L. Lonn, J. A. Jensen, and M. B. Nielsen, "Vector Flow Imaging Compared with Digital Subtraction Angiography for Stenosis Assessment in the Superficial Femoral Artery A Study of Vector Concentration, Velocity Ratio and Stenosis Degree Percentage," Ultrasound International Open, vol. 5, no. 2, pp. E53-E59, 2019.

[16] K. L. Hansen, H. Moller-Sorensen, J. Kjaergaard, M. B. Jensen, J. A. Jensen, and M. B. Nielsen, "Aortic Valve Stenosis Increases Helical Flow and Flow Complexity: A Study of Intra-Operative Cardiac Vector Flow Imaging," Ultrasound in Medicine \& Biology, vol. 43, no. 8, pp. 16071617, 2017.

[17] R. Moshavegh, B. Martins, K. L. Hansen, T. Bechsgaard, M. B. Nielsen, and J. A. Jensen, "Hybrid segmentation of vessels and automated flow measures in in-vivo ultrasound imaging, " Ultrasonics Symposium (IUS), 2016 IEEE International, pp. 1-4 2016.

[18] K. L. Hansen, "Vector concentration:a new ultrasound parameter for stenosis assessment using Vector Flow Imaging," Diagnostic Imaging Europe, pp. 19-21, 2019.

[19] "Randomised trial of endarterectomy for recently symptomatic carotid stenosis: final results of the MRC European Carotid Surgery Trial (ECST)," Lancet, vol. 351, no. 9113, pp. 1379-1387, 1998.

[20] G. Cloutier, L. Allard, and L.G. Durand, "Changes in ultrasonic doppler backscattered power downstream of concentric and eccentric stenoses under pulsatile flow, "Ultrasound in Medicine \& Biology, vol 21, no. 11, pp. 59-70, 1995.

[21] A.C.E.M. Saris, H.H.G. Hansen, S. Fekkes, J. Menssen, M.M. Nillesen, and C.L. de Korte, "In Vivo Blood Velocity Vector Imagin Using Apadtive Velocity Compunding in the Carotid Artery Bifurcation," Ultrasound in Medicine \& Biology, vol. 45, no. 7, pp. 1691-1707, 2019.

[22] A.S. Jahromi, C. S. Cina, Y. Liu, and C. M. Clase, "Sensitivity and specificity of color duplex ultrasound measurement in the estimation of internal carotid artery stenosis: a systematic review and meta-analysis," Journal of Vascular Surgery, vol. 41, no. 6, pp. 962-972. 2005.

[23] P. Tortoli, M. Lenge, D. Righi, G. Ciuti, H. Liebgott, and S. Ricci, "Comparison of carotid artery blood velocity measurements by vector and standard Doppler approaches," Ultrasound in Medicine \& Biology, vol. 41, no. 5, pp.1354-1362, 2015.

[24] R. Pizzolato, J. A. Hirsch, and J. M. Romero, "Imaging challenges of carotid artery in-stent restenosis," Journal of Neurointerventional Surgery, vol. 6, no. 1, pp. 32-41, 2014.

[25] B. K. Lal, R. W. Hobson 2nd, J. Goldstein, E. Y. Chakhtoura, and W. N. Duran, "Carotid artery stenting: is there a need to revise ultrasound velocity criteria?"Journal of Vascular Surgery, vol. 39, no. 1, pp. 58-66, 2004.

[26] A. Gupta, G. Gialdini, M. P. Lerario, H. Baradaran, A. Giambrone, B. B. Navi, et al., "Magnetic resonance angiography detection of abnormal carotid artery plaque in patients with cryptogenic stroke," Journal of the American Heart Association, vol. 4, no. 6, pp.e002012 2015.

[27] E. S. Bartlett, T. D. Walters, S. P. Symons, and A. J. Fox, "Quantification of carotid stenosis on CT angiography," AJNR American Journal of Neuroradiology, vol. 27, no. 1, pp. 13-19, 2006.

[28] J. M. Wardlaw, F. M. Chappell, M. Stevenson, E. De Nigris, S. Thomas, J. Gillard, et al., "Accurate, practical and cost-effective assessment of carotid stenosis in the UK," Health Technology Assessment, vol. 10, no. 30, pp. 1-182, 2006

[29] J. I. Meyer, R. M. Khalil, N. A. Obuchowski, and L. K. Baus, "Common carotid artery: variability of Doppler US velocity measurements, " Radiology, vol. 204, no. 2, pp. 339-340, 1997. 